\title{
Review on the Applications and the Handling Techniques of Big Data in Chinese Realty Enterprises
}

\author{
Danyang Du • Aihua Li • Lingling Zhang • \\ Huijia Li
}

Received: 1 October 2014 / Revised: 1 November 2014 / Accepted: 10 December 2014 /

Published online: 11 January 2015

(C) Springer-Verlag Berlin Heidelberg 2015

\begin{abstract}
Big data has received high attention from different industries and functional areas for now. At present, the applications of big data in Chinese real estate enterprises have achieved some success, while the systematic research about this is not sufficient so far. This paper focuses on the present applications of big data in Chinese real estate development and marketing. It suggests that the applications of big data in realty benefits diversified development and innovative investment, and it is conducive to realty marketing. The principle of the MapReduce is shortly introduced as one of the most popular big data handling techniques, and the realty big data processing and analysis based on MapReduce are shown. Adequate attention is paid to the problems of the big data applications. It proposes specific solutions to deal with the problems on big data and the problems on realty enterprises. It points out the advantage of big data applications and the future developments both in academia and industry.
\end{abstract}

Keywords Big data $\cdot$ Chinese realty enterprises $\cdot$ Application status

D. Du · A. Li (凶) $\cdot$ H. Li

Central University of Finance and Economics, Xueyuan South Road 39, Haidian District,

Beijing 100081, China

e-mail: neu_aihua@126.com

D. Du

e-mail: idudanyang@126.com

H. Li

e-mail: lihuu2000@126.com

L. Zhang

Management School, University of Chinese Academy of Sciences, Kexueyuan South Road 6,

Haidian District, Beijing 100080, China

e-mail: zl1933@163.com 


\section{Introduction}

The explosion of data volume fueled by stunning and exciting advances in computer technology and Internet techniques made big data the focus of widespread attention. As early as 2000, in the first few weeks of Sloan Digital Sky Survey the data size observed by telescope in New Mexico is bigger than that has been collected in the entire history of astronomy. Big data almost derives its origin from astronomy [21]. In addition to natural science such as astronomy, biomedicine, geoinformatics and other fields easily accompanied by enormous data volume, big data is widely known in social life. Especially in recent years, the appearance of cloud computing speed up the arrival of "the era of big data". It says that Google and Baidu have to deal with dozens of petabytes every day; there is a video length of over one hour released on the YouTube per second; there are more than one billion Facebook accounts uploading almost ten million photos every day with "like" and comment up to billions; Taobao generates about 20TB data every day with over 35 billion transactions on November 11 th $[10,20,21,25]$. This size of data is far away from the perception we had in preinformation-era society. In addition, there are more and more personal information controlled by banking and financial industry or some telecommunications industry; industrial data collected by pervasive sensors also rises sharply. As the CBC Capital chairman Tian Suning puts it, "Now, an age of mass production, sharing and application in big data is approaching."'[28]

There is no doubt that data resources are crucial in the age of big data. A number of enterprises have gained excellent decision making capabilities and immeasurable economic benefits through valuable information produced by data mining. In order to keep Chinese economic development in a sustainable, sound and rapid manner, it is very important for real estate enterprises to take full advantage of big data because of the status of real estate industry as a pillar industry of the national economy. Especially when property prices continue upward or property bubble inflation involves the national economy and people's livelihood, those real estate enterprises should make effective use of big data to tap the potentials. Solving the problems in applications on Big data, improving the abilities of investment and marketing, the estate will be able to keep playing a fundamental guiding role in national economy.

\section{Literature Review}

The history of big data is more recent compared with the recognition of the usual data. So is the related academic research. Actually, it received high attention from academic and industrial sector at once presented, followed by the big data boom both in theory research and practical application. Chinese property enterprises seize opportunities in time making successful practices, though the systematic research about the applications in big data in academia is not sufficient so far.

It is McKinsey that first puts forward the concept of big data. Big data has become an important factor of production permeating into different industries and functional areas for now. The mining and applications of large data means a new wave of productivity growth and consumer surplus [19]. Viktor Mayer-Schönberger stared the research 
on big data. He is also known as the prophet of the era of big data. He made a point that prediction is the core of big data. The transformation from samples to the overall data, the change from the pursuit of exactness to acceptance uncertainty and the correlativity instead of causality are indispensable to prepare for the age of big data [21]. He also studied how to make a choice from complicated data volume and then how to build the positive healthy future [20]. The Nature made big data special issue as early as 2008 , describing the potential value of big data and the challenge from data handling techniques in Internet technologies, biomedical and environmental sciences, cloud technologies and other fields. Likewise, the Science, one of the top international academic journals, published a special issue to convey the ideas of the time of big data. In 2012, the European academy of informatics and mathematics studied big data systematically including the management of big data, the direction and results of academic research [10]. In the area of applications of big data in realty, Lohr S. holds the view that the property sales forecasts for the next quarter depended on big data is much more precise than that made by economists [18]. Brown B and Chui M et al. believe that the reaching of big data provides potential for both realty enterprises and realty buyers with direct data sharing, bypassing the estate agents. And this can be a shock to the sense of data property right [3].

The Ministry of Industry and Information Technology (MIIT) stressed four innovative projects on key techniques including information processing technology in the "twelfth five-year" plan in December 2012, though "big data" was not official definition then. The information processing technology such as mass data storage technique and video image intelligent analysis is closely related to big data. With the time of cloud, big data is not only the IT hot word but also the focus of academic study. Studying a lot, Wang Shan at RenMin University of China illustrates the performance objectives of big data analytics platform. She reviews the framework of big data warehouse designed for analysis, supplying theory base for the structure of big data [25]. Li Guojie and Cheng Xueqi at the Institute of Computing Technology in the Chinese Academy of Sciences make a systematic exposition on the academic development of big data and the challenge in applications from a scientific research perspective, coming up with the implications of big data study [10].

The present domestic researches center on fields with large amounts of data easily available, such as library information management system and the building of digital library, the influence of big data to culture and media, the business marketing and accounting context with big data, the micro-miniature credit management based on big data, diseases control and prevention depended on big data, and so on [16]. In spite of some achievements, the applications of big data in a few certain fields are more advanced. For example, there are quite a few portal sites support big data sharing and communication, while the academic research on big data resources or how to value these resources is deficient. And the studies on the range of issues of data sharing or transaction are less. Similarly, the academic research on big data of real estate is also behind the realty entrepreneurs' practice. Chen Dachuan and Zhang Baoshan studied the application of big data in housing information system to propose the building of big housing database in 2012 [5]. Yan Juan studied the realty enterprises' precision marketing based on big data in 2013 [15]. By now, the research is not in-depth or complete enough compared with the practical applications. 
There are the following contents in this paper. Section 1 is a brief introduction for big data and the application in real life. Section 2 is a literature for big data and application in real estate market. Section 3 analyzes the application of big data and the big data handling techniques in Chinese real estate enterprise. And Sect. 4 analyzes the problem for the application of big data in real estate market and proposes the solution. And Sect. 5 summarize the paper.

\section{The Present Applications of Big Data in Chinese Real Estate Enterprises}

Regarding big data as the "future petroleum resource", White House stared the Big data Research and Development Program [10]. It is apparently to us to get the point. At the industrial level, the age of big data likely offer an even greater space for growth for those enterprises with a huge number of data and advanced data handling techniques. It seems that the property bubble is not endless and the housing price will back suitable sooner or later [30]. Then it's the key to realty development and marketing for Chinese real estate enterprises to use big data effectively.

Those huge numbers of data with variety and complexity brings new revenue model and vast space for development. In current applications of big data, the realty enterprises including developers, agency and property management companies all expand multiple comprehensive business domains. The realty development operation, intermediary services and property management are bound together inextricably. Mainly, this paper centers on realty development and marketing to illustrate the current applications of big data in Chinese real estate enterprises.

\subsection{The Applications of Big Data in Realty Development}

Big data provide strong support for a more rational way to develop. The big data remaining for potential value is conducive to diversified investment. The digital personal information and the revolutionary changes in the way of thinking make innovative investments the new revenue growth opportunities for realty enterprises in the age of big data.

\subsubsection{Rational Investment and Diversified Development}

There are more than 660 cities in our country with different housing price and different appetite for investment. There are also diverse natural environment and situation on economic development in different regions. The real estate market is still rising steadily overall, but the phenomenon of ghost towns of empty houses seriously deviates from developers expectation. Fortunately, the history of real estate is long enough for these enterprises to possess large numbers of data, such as geographic location, situation on economic development, urban planning and policy orientation, investment under construction, the land market competition, and so on. Using an advanced method to analyze the big data, these enterprises could be able to forecasts the supplies and demands and then value the investment to make a wise decision. Though this unstructured data is disordered, some even useless, the size of the data is big enough to make 
up the inaccuracy [21]. The more, the better. Google may be the pioneer in big data prediction. Before a potential pandemic influenza outbreak in 2009, google provided precise indicators swiftly by analyzing the relationship between searching key words collected from 2003 to 2008 and actual cases. That helped the US CDC get more chances. Likewise, google estimate the demand-supply equilibrium and predicted the price index in realty market successfully. While they need only to analyze stored data, and make the mathematical modeling, manipulation and comparison. Google is several times the efficiency of the government at a fraction of the cost [34]. That is the charm of the big data.

Land resources are very important for realty enterprises. The big data provides the potential for real estate enterprises to have access to explicit land market information. Realty enterprises should attach importance to the land market and pay attention to the market trend. China Vanke Co., Ltd .always concentrates on residential market, and its data on land resources almost come from the third party. Facing the constantly climbing land prices, Vanke analysis the big data to get land in the secondary market, or from the "three old" transformation, or the affordable housing construction land. It's benefit for realty enterprises to analysis big data of land resources to deal with the rising land price. "Holding on residence, no property hoarding and no land hoarding" is the big data strategy of Vanke [36].

Apart from supply-demand analysis or buying land reasonably, the applications of big data in diversified investment within the business-wide also bring massive profits. Wanda Group and Greenland Group and some other companies take the opportunity of big data to expend their business diversely to hotel and traveling commodity service, exploring profit space out of housing market. As Viktor says, the recycle of data can reveal its potential value instead of depreciation [21]. The big data not collected for diversified investment at first may debring extra profit through professional analysis.

\subsubsection{Innovative Investment}

It's good for rational development and diversified investment to analyze previous data of investment and sale. However, these enterprises, especially the bigger ones, possess more than that. The data of buyers' personal information is also considerable, and this information is far more than the name, family structure, incomes and purchasing intent. More and more personal information are getting easily available due to the development of the Internet and the spread of computers in era of big data. A lot of information that used to be meaningless for real estate such as the buyers' habits and customs and the preferred travel routes will be revealed by mining these data. Although these data isn't so structured, the potential value is great. It means new opportunities for realty development and breakthroughs of benefits.

Vanke Group and Fantasia Group, two of the leader realty enterprises, also stay ahead of the applications of big data. Based on consumer demand, Fantasia planned to build community e-commerce creatively, combining commercial tenants with customers through app on cellphones. Holding millions of homebuyers' data, Fantasia is able to establish a convenient efficient platform for accurate marketing. This advantage of big data will help Fantasia to improve strength at the same time. In addition to community e-commerce, Fantasia expands its big data business based on the Mobile 
Internet to other eight areas, such as financial sector, hotel services, culture and tourism. It seems that Fantasia is far away from traditional real estate enterprise [2]. The improving big data handling techniques bring tremendous business opportunities to Vanke Group in the same way. The 4.8 million property owners means an enormous amount of wealth for Vanke as the realty almost become manufacture nowadays. After data processing, Vanke put forward the concept of building city support services, combining community logistics, medical services and pension with the 4.8 million property owners' big data. It will bring a great opportunity [23].

The innovative investment made by Shimao Group is more remarkable compared to Vanke and Fantasia. As its business ideas state, the homebuyers prefer an experience of a lifetime rather than a mere house in the future. Therefore Shimao introduced the "health clouds" business management to its property owners for the health monitoring and advisory opinion. Analyzing the monitor data collected by some mobile devices like cellphones and watches in real time, they can produce a health scheme, preparing for disease and helping these owners keep healthy or providing them with hypostatic medical service [23]. Taking advantage of big data, other enterprises like Gold Ground Group and Green Ground Group also open up new operations such as Intelligent City and Cloud Service in succession. These enterprises pay more attention to consumer's satisfaction of spirit and psychology instead of a shelter. Better service for customers matter a lot.

The applications of big data in innovative investment are common occurrence at foreign real estate enterprises. The classical case, Windermere Real Estate, is popular in American college textbooks. They plan for the potential buyers with their commute routes and the cost of time by analyzing information from nearly one hundred million drivers' GPS [27]. This innovative business not only meets the customers' demand with improving quality of service, but also promotes the realty seals. That's worth considering (Table 1).

\subsection{The Applications of Big Data in Realty Marketing}

In fact, there are over-developed real estates in some medium and small cities in our country. House is essentially a special consumer good while the seemingly substantial benefit attracts large amounts of investment. Actually, the attraction there is far less than tier one and tier two cities leaving the vast number of vacant houses. Therefore, how to use big data to promote sales is crucial. In addition, traditional marketing models are ineffective as the popularization of electronic commerce is changing the consumption manners of the Chinese. The prospects of realty marketing are not so bright.

To deal with these issues, above all, is to market successfully in the era of big data. Data resources are very important for realty enterprises to raise competitiveness. The huge and perfect sources of data ensure precise customer location and the effective marketing. At first, real estate enterprises can implement precise marketing relying on information system. They can build the customer data system based on the possession of big data to categorize the customers, then extract useful information by big data mining for the precise marketing [15] (Fig. 1). 
Table 1 The applications of big data in realty development

\begin{tabular}{|c|c|c|}
\hline Enterprise & The big data resources & Realty development and investment \\
\hline Google & Key words & $\begin{array}{l}\text { Estimate the demand-supply equilibrium } \\
\text { and predict the price index in realty market } \\
\text { by analyzing the relationship between } \\
\text { searching key words and the data of } \\
\text { housing price, providing strong support for } \\
\text { rational developments }\end{array}$ \\
\hline Vanke & Land resources & $\begin{array}{l}\text { Analysis big data of land resources to deal } \\
\text { with the rising land price }\end{array}$ \\
\hline Wanda, Greenland & Realty development & $\begin{array}{l}\text { Reveal potential value of big data for } \\
\text { diversified investment }\end{array}$ \\
\hline Fantasia Group & Buyers' requirement & $\begin{array}{l}\text { Build community e-commerce creatively and } \\
\text { expands its big data business to financial } \\
\text { sector, hotel services, culture and tourism }\end{array}$ \\
\hline Vanke & Owners' personal information & $\begin{array}{l}\text { Put forward the concept of building city } \\
\text { supporting services }\end{array}$ \\
\hline Shimao Group & Owners' health conditions & $\begin{array}{l}\text { Introduce the "health clouds" business } \\
\text { management to its property owners for the } \\
\text { health monitoring and advisory opinion }\end{array}$ \\
\hline Goldland, Greenland & Owners' personal information & $\begin{array}{l}\text { Open up new operations such as Intelligent } \\
\text { City and Cloud Service }\end{array}$ \\
\hline Windermere & Information from drivers' GPS & $\begin{array}{l}\text { Plan for the potential buyer with their } \\
\text { commute routes and the cost of time }\end{array}$ \\
\hline
\end{tabular}

In addition, some large estate enterprises change marketing patterns, actively turning to e-commerce. Xinfeng real estate created five big data application system last years. The resources decision support system, the house book network and Xinfeng automated assessment systems are part of the five systems already running with high performance. The houses book network can select certain houses according to the users' demand. The automated assessment systems can evaluate the housing price automatically depended on the big data processing. Once the users input the data of the conditions it will estimate the price and other information like loan and mortgage or the transaction tax. It's impossible without advanced big data processing technique. Xinfeng made realty e-commerce the same as Wanda Group, combining online services with offline services. The offline sales departments also get in touch with customers according to the online information [31]. This marketing pattern requires excellent technique on data collection, storage and analysis. So the estate enterprises should master the data processing technology as well as the big data.

Those marketing models above all widen existing business domain proactively without the third-party. In Viktor's opinion, if the estate enterprises are willing to share data, they can cooperate with the third-party, joining up with the market players like developers and home services and customers, fully demonstrating the advantage of big data. For example, the CNFS real estate big data system includes data of 289 cities ranging from government to the estate enterprises even the Second-hand housing 


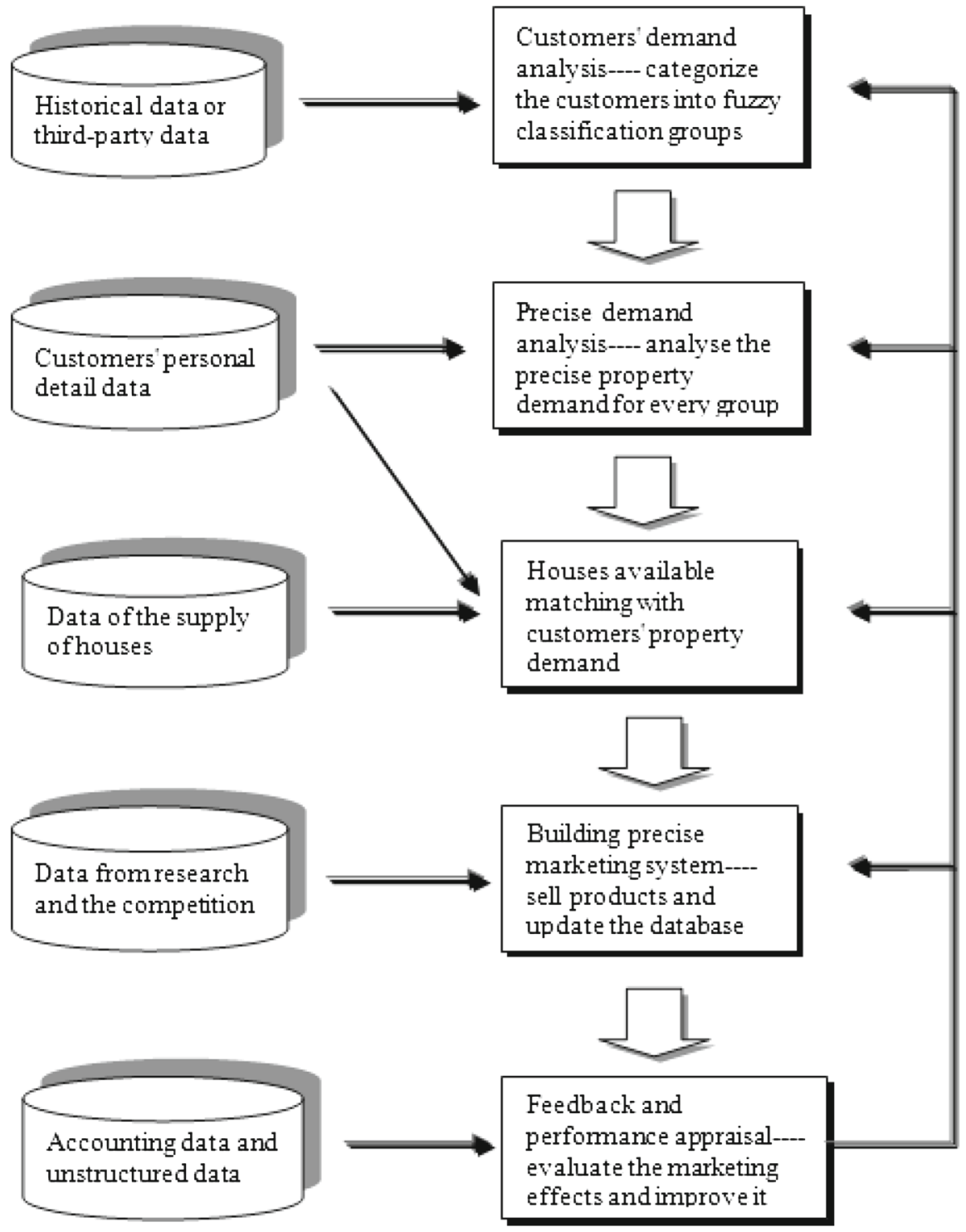

Fig. 1 Realty precise marketing flow chart

market, and some reach a length of ten years. There is no doubt that the data are only collected and processed by CICC [12]. Realty Mogul bridges opportunities of small investments between estate enterprises and investor via the Internet crowd funding. The information and analysis result provided for investors all come from its possession of big data [37]. E-house China is rather typical for the asset-light strategy, leading a diverse scope of services in Chinese realty estate. E-house introduces the China Real Estate Information Circle servicing for over one million property buyers. Depended on 
Table 2 The applications of big data in realty marketing

\begin{tabular}{|c|c|c|}
\hline Enterprise & The big data resources & Marketing patterns \\
\hline Xinfeng & $\begin{array}{l}\text { Property information, } \\
\text { Buyers' demand }\end{array}$ & $\begin{array}{l}\text { Create five big data application system to } \\
\text { recommend certain houses and evaluate } \\
\text { the housing price }\end{array}$ \\
\hline $\mathrm{CICC}$ & $\begin{array}{l}\text { Transaction data in different } \\
\text { places }\end{array}$ & CNFS real estate big data system \\
\hline Realty Mogul & $\begin{array}{l}\text { Realty information, investor' } \\
\text { ability }\end{array}$ & $\begin{array}{l}\text { Bridge opportunities of small investments } \\
\text { between estate enterprises and investor }\end{array}$ \\
\hline E-house China & $\begin{array}{l}\text { Historical transaction } \\
\text { information }\end{array}$ & $\begin{array}{l}\text { Lead a diverse scope of services and } \\
\text { introduce the CRIC }\end{array}$ \\
\hline Haowu & Buyers' personal information & $\begin{array}{l}\text { Establish the big data warehouse, then match } \\
\text { the buyers' demand with the house } \\
\text { available }\end{array}$ \\
\hline Ifeng & Page views of users & $\begin{array}{l}\text { Get their customers' demand better and } \\
\text { market more precisely by analyzing big } \\
\text { data effectively }\end{array}$ \\
\hline $\begin{array}{l}\text { Tencent qqfangshi } \\
\text { \&Country Garden }\end{array}$ & $\begin{array}{l}\text { Data on social network } \\
\text { software }\end{array}$ & $\begin{array}{l}\text { The big data on Internet platform provide } \\
\text { realty enterprises with precise marketing } \\
\text { pattern based on habits data of users }\end{array}$ \\
\hline
\end{tabular}

advanced IT, the big data with low cost brings considerable profit [7]. There are many similar third-party marketing platforms, such as SouFun, Myfun, Real Estate Network, Ifeng, and so on, possessing advanced Internet and data processing technology for big data collection and storage. Some realty platforms have made great achievements like Fangdd and Haowu, though the history of realty estate e-commerce is short. Haowu absorbed huge number of buyers' personal information, and established the big data warehouse, then matched the buyers' demand with the house available through certain algorithm, promoting the sales successfully [32]. There are 1.6 million page views on Ifeng. That makes the customers' demand well available, so they can market more precisely by analyzing big data effectively. The thought on big data will promote the real estate. Ever since the introductions of Instant Messenger, there are more and more users registered. In March of last year, the cooperation between Tencent qqfangshi and the Country Garden made a marvelous success on realty marketing with 3300 houses available at the opening. This is a win-win situation - the big data on Internet platform provide realty enterprises with precise marketing pattern based on habits of users; meanwhile the realty buyers' information online is used for the update of the Internet platform [22]. Other famous enterprises like Longfor Group ever attempted group-buying, making effort to build the realty TaoBao (Table 2).

\subsection{Big Data Handling Techniques in Real Estate Enterprise}

The perfect applications of big data in Chinese real estate enterprises depend on the development and the current practice of big data handling technologies. The big data means volume, velocity, variety and veracity. It is necessary for realty enterprises 
to catch new different techniques in data acquisition, data storage and the analytical processing given the feature and demand analysis of big data. There are some big data handling technologies such as Massively Parallel Processing, Bata Mining, Distributed File System, Distributed Database, Cloud Computing Platform, Internet and Extensible Storage Systems so far, made it possible for realty enterprises to reach the great value of the big data [17].

\subsubsection{Overview of MapReduce Programming Model for Realty Big Data Processing}

As the realty big data resources are mostly the Web and mobile communication, the combination of big data handling technology and internet and information technology is pretty critical for the significance of applications of this data. Baidu and Vanke made an announcement for strategic cooperation June 5th this year that Baidu will supply Vanke with the solutions of upgrade for intelligential by big data processing technology and the Cloud Computing. Cloud Computing is an infrastructure for big data processing technology and cloud technology is the most important and effective technology to solve these big data problems so far. While the big data form a rich accumulation of information by actual data collection. It's a significant application area of cloud technology. That is to say, big data processing technology and cloud technology make it each other possible.

Cloud Computing is the key technology for most search engines and browsers to collect and massage the data. This makes it possible for users to gain a supply of needed resources and services via the easily-extensible way on demand. Based upon the Internet, Cloud Computing automatically splits the enormous computer program needed into numerous minor subprograms via the existing network. After searching, compute and analysis by a bigger system comprising many servers, the result sets are passed on to the users. The volume of big data is so huge that a powerful storage device is desperately needed for the Cloud Computing system to build cloud storage system. This has significant implications for data storage and management. The concept of cloud storage involved in the applications of big data in Chinese realty enterprises is included in Cloud Computing. Using clustered applications, network technologies, distributed file systems and so on, cloud storage brings together the large number of various storage devices by software applications to make them work together, together providing real estate enterprises with data storage functionality and service accessing functionality. Depending on different data resources realty enterprises will be able to get resource services of a wide range of specifications on compute, storage and network [35]. Based on demand, the fast creating and release of computing resources on the network bring effective analysis and management of the huge number of data, achieving the successful applications of big data. Realty enterprises are able to build the intelligent city by suing Cloud Computing for the big data storage and processing. Actually, the cloud computing centers will deal with these data of health care, traffic and security in the background, providing the basis for the building of intelligent city [4].

Magnanimous data-storage technique, magnanimous data-management technique and MapReduce programming model are not only the key techniques of Cloud Computing, but also the base of big data handling technique. Among them, the MapReduce, one of the Google's three magic technology weapons, is designed for the solutions 
to the huge volume non-real-time data processing problem, making extensive data processing running in parallel. In essence, there is no notable difference between the basic big data handling process and the traditional big data handling process except the applications of parallel processing technique in every components as the large-scale data required.

MapReduce contains Map and Reduce. The main principle of Map is division of work. Map makes the traditional inquire task, disassembling task and data analysis task into distributed processing, allocating handling task to different nodes and satisfying the requirement of high level parallel processing. The main principle of Reduce is combination of work. Reduce combines different information coming from the Map, computing the result sets and achieving the reduced answer. Map and Reduce are combined by Shuffle, inputting from Map and outputting from Reduce [8].

For the applications of big data in Chinese real estate enterprises, the realty big data information demander starts the task requirements first. The Server sponsors these associated processes including a Master and some Map workers and Reduce workers. The Job tracker in the Master distributes the data processing task to different Map workers, leaving different workers with different data sets. That means some data set is handled by only one certain worker. Every Map worker is companied by a Task tracker and the Job tracker monitors every worker via the Task tracker. The Job tracker will conclude that there's something wrong with some Map node or Reduce node when the feedback is wrong, and then ends the processing of this wrong node, leaving the data processing task to other nodes. The result coming from Map will be leaved in the cache. But, these results will be writing on the disk when memory is so low that they cannot continue to store the results. These results are writing into different partitions of the disk and the partitions have the same number as the Reduce. The Master divides the partitions for every Reduce worker, and the worker identifies its exclusive partition from the Maps [1]. Sorting and combining the data, Reduce workers calculate with functions, outputting the result and converting it into the form of realty enterprises' demands. With the parallel processing capabilities, MapReduce turns traditional query, decomposition and data analysis into distributed processing tasks, leaving handling task to different nodes where data consistency was not seen as important. The outstanding is its extensibility and practicality. Therefore, real estate enterprises can handle extremely large amounts of structured data, semi-structured data or non-structured data together, greatly enhancing the efficiency [13] (Fig. 2).

MapReduce achieved the large-scale data parallel processing, extremely improving data processing speed. On one hand, this reflects the characteristics of the big data itself, and on the other hand it includes the realty enterprises' demands on the value of big data. Hadoop is one of the best tools for big data processing and analysis. At first, MapReduce is the core component of Hadoop, while those product and service supported by Hadoop2.0 will introduce SQL query engine or other methods instead of MapReduce, such as HBase NoSQL data base. This is a non-relational distributed database, with the structured extensive data storage capacity. Many large Internet companies such as Facebook, eBay and others have started using HBase to deal with transactional applications. Programming is one of the important foundations of MapReduce. The certain program depends on different business, reducing 


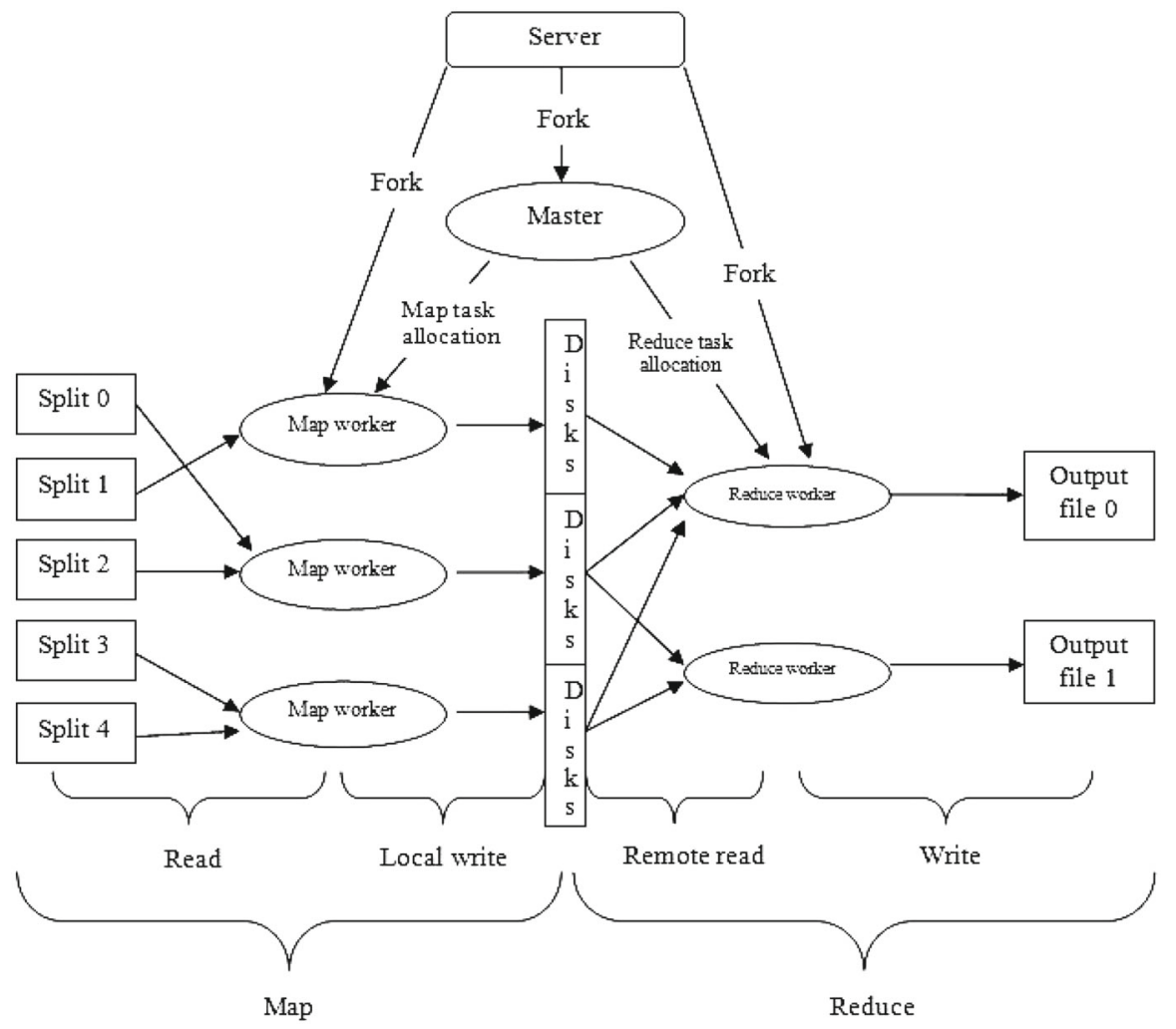

Fig. 2 MapReduce programming model for realty big data processing

the recycling utilization ratio of programs. In the future, combined with SQL, SQLMapReduce is expected to break through the technology barriers, meeting different demands of different enterprises.

\subsubsection{The Realty Big Data Processing and Analysis Based on MapReduce}

The above-mentioned techniques can be applied to the realty big data processing and analysis. Generally speaking, the whole disposed process includes four phases: data acquisition, data introduction and pretreatment, data statistics and analysis, data mining.

These data stored in realty enterprises are usual structured, and they can be collected via specific system interfaces. But these data are restricted to operation or accounting. Actually, it is the customer data and the proprietor data that mean unlimited potential though these data are not so structured in general. In this sense, realty big data acquisition means receiving the data coming from the clients-Web, App and sensors-via multiple databases. And users are allowed to do some simple query or process via these databases. For example, some realty enterprises turning to e-commerce can use traditional relational database such as MySQL or MySQL to store each business data. 
The main characteristic or challenge of the big data acquisition phase is the high concurrency. Therefore lots of databases deployed in data sample module are indispensable. Collecting data of customer information and market information requires a high level of data acquisition capacity in realty enterprises. Or they can make strategic cooperation with some internet firms for big data acquisition. Many internet companies have their own big data acquisition systems, such as the ChukWa of Hadoop, Flume of Cloudera, Scribe of Facebook and so on. These systems are mostly used to collect the system log. Taking ChukWa as an example, based on the HDFS (Hadoop Distributed File System) and MapReduce of Hadoop, it inherits the scalability and robustness from Hadoop. ChukWa is made up made up of agents, adaptor, collectors, map/reduce jobs and HICC. Adaptor is the interface tool for direct data acquisition. Agents collect the original data and then send them to collectors. Every agent supervises several adaptors for the data acquisition. In charge of the reception of big data gathered by agents, collectors write them to clusters regularly. Map/reduce jobs start regularly to manage the classification, ordering, duplicate removal and merging of big data in clusters. The HICC (Hadoop Infrastructure Care Center) displays these contents. For unstructured data, the acquisition of network data means collecting data information from the network through the Web crawler technology or the public website API. Extracting unstructured data from the webpage, it stores these data as unified structured local files. This supports the collection of pictures, audio files, video files and attachments, associating attachments automatically with the main text. Excepting the content included in webpage, some bandwidth management technologies such as the DPI and DFI are often used for network traffic data collection [11].

In order to analyze these massive amounts of data effectively, these data from front end should be imported into a centralized large distributed database or a distributed storage cluster, though there are lots of databases in the sample module. After that, some simple data cleaning and preprocessing is needed. The main characteristic or challenge of data introduction and pretreatment phase is the huge volume of the datait may be 100M even Giga-level per second. The superiority of the Hadoop cluster in storage and computation is conducive to distributed data cleaning. The idea is to expand the storage and computation to the various nodes in Hadoop cluster because of the demand for tremendous computing power during the big data cleaning process. It can improve the parallelism and accuracy in the cleaning process of massive data. The HDFS and MapReduce are the core pieces of Hadoop. HDFS, the Hadoop distributed file system, implements the data storage and management, while the MapReduce implements the data cleaning in parallel. HDFS provides different interfaces. We can simply check these data and files through API or the operations command. Based on HDFS, we can import huge amounts of data from heterogeneous sources, providing data cleaning engine with data input and the resulting output. The other important part of Hadoop is the MapReduce process. It provides the interactive connection among different modules, and the compute tasks of every module can be published to the compute nodes in the Hadoop cluster. Sometimes the operation control is essential to multiple jobs during the process of parallelization, making the output of an earlier job the input of a subsequent one. If the output of an earlier job cannot be input directly, this output will be positioned over the HDFS according to the specified format. The subsequent job can read it directly from the file when needed [38]. 
Mainly by distributed databases or distributed computing cluster, data statistics and analysis can achieve general classification and subtotal of large data volumes stored in it to address these most general needs. The statistical analysis on the realty big data tends to be large consumers of resources. That may be a great challenge for most real estate enterprises.

But, unlike the data statistics and analysis phase, generally no subject defined beforehand is needed in data mining phase. Based on various algorithms, it makes some calculations on these available realty data for predictions and meeting some high-level data analysis needs. There are some more typical algorithm: K-means for clustering, SVM for statistical learning and Naïve Bayes for classification. And the major tools are Hadoop, Mahout and so on. This usually means massive amounts of data and complex computation [33]. Based on Hadoop cloud computing framework, we can build a distributed data mining platform integrating the data storage, analysis and processing for the parallel algorithm. With the clustering algorithm, for example, the process based on cloud computing as follows. 1. The data set to be processed is divided into several data blocks stored in HDFS in Hadoop cluster. According to the perception of Hadoop, every data block is processed by Mapper-function in the MapReduce process. 2. The distance between the cluster center and each node is calculated by the Mapper-function, and then assign this node to the nearest clustering. The coordinate of this node and the label of this cluster are output in the end. 3 . The information on the coordinates of all the nodes in each cluster is sent to Reducer. Then the new cluster center will be calculated by the Reduce-function with the output of the label of this cluster and the new cluster center. 4. Comparing the new cluster center with the previous one, it's the termination of this algorithm if they are the same. Otherwise, execute step 2-step 4 iteratively. [14]

These phases are the complete realty data handling processes. Combining the big data processing with analytical visualizations, data mining algorithms, predictive analytical capabilities, semantic engines, data quality and master data management, Chinese real estate enterprises will be able to make full use of big data to learn valuable information for rational investment, innovative development and diversified marketing.

\section{The Problems of Applications of Big Data in Real Estate Enterprises and the Solutions}

Big data is new and filled with possibilities. Estate enterprises should pay more attention to the challenges and potential problems while taking advantage of big data for development and marketing. The contradictions between privacy protections and big data are irreconcilable. The big data processing technology is not easily available for most enterprises. In addition, the characteristic of real estate corporations bring more challenges into the applications of big data.

\subsection{The Problems on Big Data and the Solutions}

It's inevitable to get enough personal information when the estate enterprises provide specific services for different customers. If the size of the data is big enough, recogni- 
tion rates of the personal identity can reaching more than $99 \%$ even without personal information [21]. According to present ethics and moral concept it's impossible for us to ignore the big data containing much personal privacy. To deal with this problem, Viktor prefers the data users rather than the possessors to take responsibility of privacy protections or making the personal information indistinct deliberately to give up some precision for the protection of personal privacy [21,29]. Whether it works or not has to be studied further.

Big data encompasses much more than just lots of number. It's more complex and disordered. The collection, storage and processing of this enormous unstructured data needs unusually advanced technology. The generation of big data is fast and sustained with lower and lower value-density. It's a big challenge for any estate corporation to capture the sort of useful information from the large numbers of multifarious data. On the one hand, to make national big data strategies and to promote the process of academic study on big data and the conversion of research achievements into realistic productivity will help estate corporation improve the big data handling capabilities. On the other hand, it may be a good choice for real estate enterprises to have big data handled by professional third parties. Different types of companies play different roles at the age of big data. The estate corporations can center on the applications of information to deepen development, leaving big data processing to third-parties excellent on technology [9].

Great importance should be attached to international exchange and cooperation in the era of big data. Meanwhile, real estate enterprises should pay attention to the possible impact making by foreign advanced technology on applications of big data. Seeing the big data in Chinese market, several foreign companies want to enter the market for the big data business, while there is no comparable domestic enterprise being able to counter that at present. Under this condition domestic companies should cooperate with the foreign at first, promoting the internationalization of big data business. Meanwhile appropriate operation model and the status of both sides matter a lot. The foreign companies play role of middlemen and the domestic companies should keep the property right and potential value of big data [24].

\subsection{The Problems on Real Estate Enterprises and the Solutions}

Real estate is the mainstay of real economy with some characteristics of fictitious economy such as complexity, metastability and high risk [26], increasing the uncertainties in applications of big data. Because fictitious economy system is highly sensitive to expectation and the publicity and sharing of big data can easily impact people' expectations of realty, the investment demand can be more unstable. Given the metastability this impaction will destroy the instability of real estate, influencing national economic development. Therefore, these estate companies should be judgmatical in revolution while taking the opportunity of big data for innovation [39].

The advantage of big data is not nature for real estate other than e-commerce. There exist data structural imbalances and information asymmetry. So the platform for data sharing is a crying need. The platform should be designed for the realty data storage and it should help to build a huge real estate database referring to the Real Estate 
Appraiser' work. For example, set up and improving of housing information system is beneficial to systematical management of the data of housing monitoring, housing fund and housing security. Building a safety integrity level and limitation of independence system by designing program for data collection, warehouse and searching, the system achieves the goal of data sharing within government, enterprises and individuals [5].

More comprehensive business, wider range and more collective management are the current growing trends in real estate enterprises. Under the conditions, how to operate effectively is also a big data problem. The estate enterprises have to build a big data warehouse planning person, money, matter, and information, and carry out the integration management by data mining and analysis for predictions.

\section{Conclusions and Prospects}

The big data has become a type of significant strategic resource for estate enterprises to enhance competitiveness. At present, the applications of big data in Chinese real estate enterprises have achieved some success. The processing and analysis of big data is conductive to avoiding over-development and to coping with the rising land prices for enterprises, and it facilitates the diversified development and the innovative investment. What's more, the applications of big data in realty marketing have promoted the realty sales greatly. Nevertheless, since our exploration of big data is just beginning, the practice on this field is incomplete. There still remain quite a number of problems to be tackled such as the privacy protection, data processing technique and the challenges derived from the unique characteristics of real estate.

Further research should focus on the specific application of the big data, studying the internal methods and technology in detail. The theory and the practice complement each other. The ambitious attempt at the applications of big data in estate enterprises will deepen related research. Meanwhile, scientific research will be conducive to the splendid achievements for estate enterprises at the era of big data [6].

Acknowledgments This research is partially supported by the Grants (71401188, 71401194 and 70921061) from the National NSFC, the third 211 construction funding and Program for Innovation Research in CUFE. Part of this paper was presented at the First International Conference on Data Science (ICDS2014).

\section{References}

1. Battle LM (2013) Interactive visualization of big data lleveraging databases for scalable computation [D]. Massachusetts Institute of Technology, Cambridge

2. Big data area with billion fortune: four business domains in community services [EB/OL]. http://www. ffw.com.cn/1/107/463/169906_2.html

3. Brown B, Chui M, Manyika J (2011) Are you ready for the era of 'Big Data'. Mckinsey Q 4:24-35

4. Cloud Computing [EB/OL]. http://baike.so.com/doc/580575.html

5. Dachuan C, Baoshan Z (2012) The applications of big data in housing information system. Inform Commun Technol 5:004

6. Danyang D, Aihua L (2014) Survey on the applications of big data in Chinese real estate enterprises. Proc Comput Sci 30:24-33

7. E-House China introduced the CRIC [EB/OL]. http://money.163.com/13/0520/01/8V9GEDM3002 53B0H.html 
8. Gift Noah (2011) Solving big data problems related to cloud computing with MapReduce [EB/OL]. Developer Works, (1)

9. Guojie L (2012) The scientific value of the research on big data. China Comput Fed 8(9):8-15

10. Guojie L, Xueqi C (2012) Research status and scientific thinking of big data. Bull Chin Acad Sci 27(6):647-657

11. Hongyan L (2013) The methods and applications of BI[M]. Tsinghua University Press, Beijing

12. http://www.cnfsdata.com/default/bigdata.html

13. Huan L (2013) MapReduce: weapon for big data parallel computing. Inform Tactics 11:54-57

14. Hui W, Lijuan Z (2013) Survey on the hadoop-based parallel data mining algorithm[D]. Capital Normal University, Beijing

15. Juan Y (2013) The precise marketing based on big data in the real estate enterprises. Mark Wkly 9:66-67

16. Lianjuan C Application Practice and Beneficial Reference of Big data Promotion in the S (2013) An analysis from the perspective of library. Inform Doc Serv (005): 110-112

17. Lin Y (2013) The applications of big data. Gd Gard Sci 12:75-76

18. Lohr S (2012) The age of big data. New York Times, New York 11

19. Manyika J, Chui M, Brown B, et al. (2011) Big data: the next frontier for innovation, competition, and productivity

20. Mayer-Schönberger V (2011) Delete: the virtue of forgetting in the digital age [M]. Princeton University Press, Princeton

21. Mayer-Schönberger V, Cukier K (2013) Big data: a revolution that will transform how we live, work, and think [M]. Houghton Mifflin Harcourt, Boston

22. Realty marketing has entered the era of big data in 2013 [EB/OL]. http://gd.qq.com/a/20130309/ 000055.htm

23. Recognize the big data, the transition of realty companies needs soft power [EB/OL]. http://house. china.com.cn/chongqing/view/688439.htm

24. Ritchey D (2012) Big data, big security. Security 49(7):28-30

25. Shan W, Huiju W, Xiongpai T (2011) Architecting big data: challenges, studies and forecasts. J Comput Sci Technol 34(10):1741-1752

26. Siwei C (2009) The fundamentals and research methods of fictitious economy. Manag Rev 21(1):3-18

27. Sonka S (2014) IFAMR I. Big data and the ag sector: more than lots of numbers. Int Food Agribus Manag Rev 17(1):1

28. Suning T (2013) Embrace the era of big data. Bus Res 3:1-1

29. Tene O, Polonetsky J (2012) Privacy in the age of big data: a time for big decisions. Stanf Law Rev Online 64:63

30. The age of big data in real estate, hard to save the sunset industry [EB/OL]. http://news.nb.soufun. com/2013-07-16/10532468_all.html

31. The press conference on big data in real estate in 2013[EB/OL]. http://sy.jiwu.com/news/1301701. html

32. Wanli Y Talking within Haowu, the era of big data for independent broker [EB/OL]. http://www.pcpop. com/doc/0/931/931855.shtml

33. What's most expensive in the big data era.[EB/OL]. http://bbs.pinggu.org/bigdata/

34. Wu L, Brynjolfsson E (2013) The future of prediction: how google searches foreshadow housing prices and sales $[\mathrm{M}] / /$ economics of digitization. University of Chicago Press, Chicago

35. Xiaofeng M, Xiang C (2013) Big data management: concepts, techniques and challenges. J Comput Res Dev 50(1):146-169

36. Xishang W (2010) The statement of Vanke: not the crown, green transformation for the first-mover advantage. Stock Mark Trend Anal Wkly 13:018

37. Yan W. Realty Mogul the Internet crowd funding platform for realty investment [EB/OL]. http://www. it-times.com.cn/wangzhidaohang/20723.jhtml

38. Yizhong G, Xin Yi P (2012) Hadoop distributed data cleaning Method-The research and implementation of Hadoop data cleaning algorithm based on Outlier mining [D]. South China University of Technology

39. Zuoming L (2009) Generalized fictitious economy-introduction of dualistic values Rong-jie state. Manag Sci 1:1-8 

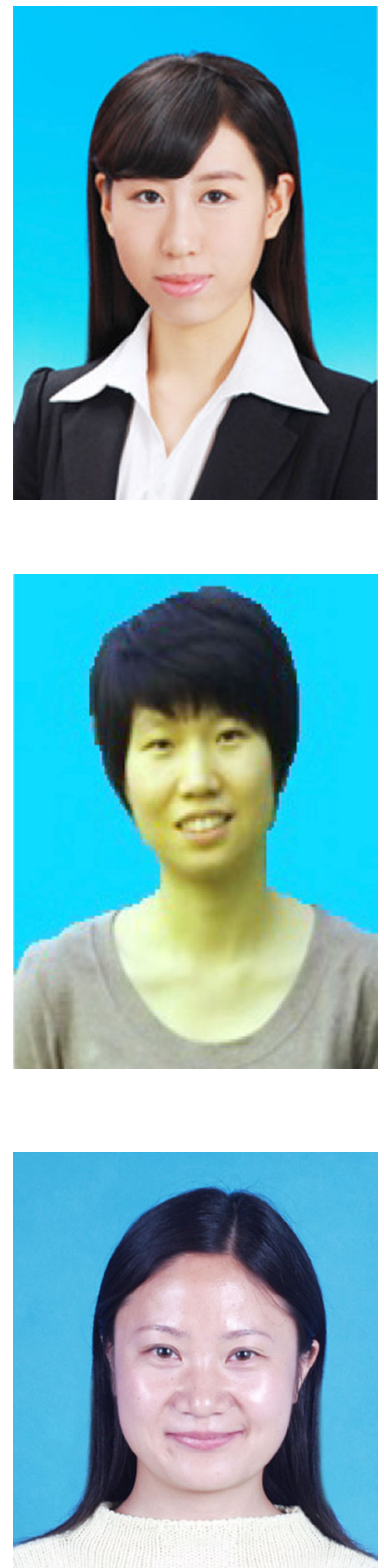

Danyang Du was born in Shandong province, China in 1990. She graduated from Business School, Shandong University, in 2013. Now she is a graduate student of School of Management Science and Engineering in Central University of Finance and Economics (CUFE), major in management science and engineering. She participated in The First International Conference on Data Science in 2014. Her research interests include data mining and real estate.
Aihua Li received the bachelor degree in Applied Mathematics from Northeast University (NEU) in 2001, and received the master degree in Operational Research \& Control Theory from NEU in 2004. She then received the Ph.D. degree from Graduate School of Chinese Academy of Sciences (GUCAS) in Management Science and Engineering in 2007. Now she is an Association Professor in Central University of Finance and Economics (CUFE). She has published more than 30 papers in national and international journals, and conference proceedings. Her research interest includes data mining theory and application, decision science, and operational research.

Lingling Zhang currently is Associate Professor at School of Management, University of Chinese Academy of Sciences. She also works as a researcher at Research Centre on Fictitious Economy \& Data Science, Chinese Academy of Sciences. She was once visiting scholar of Stanford University in the USA. Currently, her research interests include data mining, intelligent knowledge management, and management information system. She has received three grant supported by the Natural Science Foundation of China (NSFC), published 4 books, more than 40 papers in various journals. 


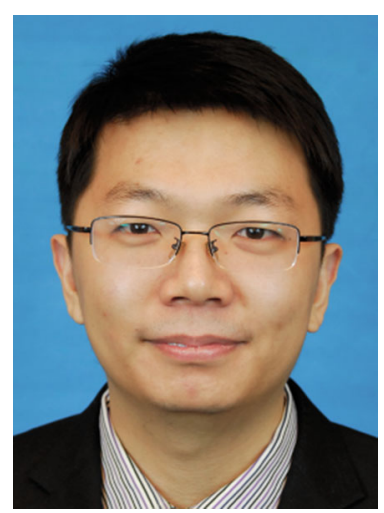

Huijia Li was born in Jining, China in 1985. He graduated and obtained doctoral degree at Academy of Mathematics and Systems Science, Chinese Academy of Sciences in 2013. Since 2013 he works as a Lecturer at School of Management Science and Engineering, Central University of Finance and Economics. He has published more than 30 papers in national and international journals, and conference proceedings in the field of data analysis and network science. His research interest includes decision science, network science, evolutionary computation and operational research. 